\title{
Assessment the effect of fentanyl and dexmedetomidine as adjuvant to epidural bupivacaine in parturients undergoing normal labor
}

Rabie Soliman ${ }^{1,2^{*}}$ and Gomaa Zohry ${ }^{2}$

*Correspondence: rabiesoliman@hotmail.com

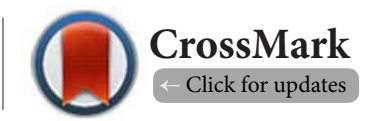

'Department of Anesthesia, Aldar hospital, Almadinah Almonwarah, Saudi Arabia.

${ }^{2}$ Department of Anesthesia, Cairo University, Egypt.

\begin{abstract}
Background: Dexmedetomidine acts on the pre and post-synaptic sympathetic nerve terminal and central nervous system. It decreases the sympathetic outflow and norepinephrine release; therefore it leads to sedation, analgesia and hemodynamic effects. The aim of the study was to compare the effect of fentanyl and dexmedetomidine as adjuvant to epidural bupivacaine in parturients undergoing normal labor.

Materials and methods: The study included 170 parturients scheduled for epidural anesthesia for labor. The cases were classified randomly (by simple randomization) into two groups $(n=85)$ : Group D: The patients received $13 \mathrm{ml}$ of $0.25 \%$ bupivacaine and $1 \mu \mathrm{g} / \mathrm{kg}$ dexmedetomidine diluted in $2 \mathrm{ml}$ saline. Group F: The patients received $13 \mathrm{ml}$ of $0.25 \%$ bupivacaine and $1 \mu \mathrm{g} / \mathrm{kg}$ fentanyl diluted in $2 \mathrm{ml}$ saline.

Results: The dexmedetomidine shortened the onset and prolonged the duration of analgesia compared to fentanyl $(\mathrm{p}<0.05)$. Dexmedetomidine was associated with an increased incidence of maternal hypotension, bradycardia, motor block, and dry mouth $(\mathrm{p}<0.05)$, while the epidural fentanyl was associated with an increased incidence of maternal pruritus, nausea and vomiting, and respiratory depression $(\mathrm{p}<0.05)$. The incidence of shivering was lower in the dexmedetomidine group compared to fentanyl group $(\mathrm{p}=0.003)$.

Conclusions: The epidural dexmedetomidine has many advantages over the fentanyl, where it fastens the onset, prolongs the duration of analgesia, decreases the doses of bupivacaine and the incidence of pruritus, respiratory depression, nausea and vomiting. Also, it is associated with some disadvantages such as maternal hypotension, bradycardia and motor block.
\end{abstract}

Keywords: Dexmedetomidine, fentanyl, bupivacaine, epidural anesthesia, analgesia, labor

\section{Introduction}

Epidural analgesia has been extensively used to provide pain relief during labor [1]. Labor pain and painful uterine contractions cause hyperventilation and high catecholamine levels, resulting in maternal and fetal hypoxemia [2]. Pain relief provides a comfort for the patients and attenuates the release of stress hormones [3]. Epidural bupivacaine is still the most widely used local anesthetic in obstetric analgesia [1]. Many drugs are added to bupivacaine to minimize its total dose and to prolong the analgesic effect [4].

Fentanyl has been used as an adjuvant for epidural local anesthetics during labor analgesia to achieve the desired anesthetic effect [5], and to decrease motor block of local anesthetics. However, the addition of opioid may increase the incidence of pruritus, urinary retention, nausea, vomiting and respiratory depression [6-8].

Dexmedetomidine is alpha-2 adrenergic agonists with analgesic properties which potentiate the epidural local anesthetic effects $[9,10]$. They act on both pre- and postsynaptic sympathetic nerve terminal and central nervous system, thereby decreasing the sympathetic outflow and nor-epinephrine release, causing sedative, anti-anxiety, analgesic, sympatholytic and hemodynamic effects [11-13]. The aim of the study was to compare the effect of fentanyl and dexmedetomidine as adjuvant to epidural bupivacaine in parturients undergoing labor.

\section{Outcome}

The primary outcome was the adequacy of maternal analgesia 
throughout labor and the secondary outcome was the safety of the intervention. The safety was assessed by the occurrence of any adverse events to the parturient and fetus.

\section{Materials and methods}

After obtaining informed consent and approval of local ethics and research committee in Aldar hospital, Almadinah Almonwarah, Saudi Arabia. A pilot study was done before starting this study to compare the effect of dexmedetomidine and fentanyl on the analgesic effect of epidural bupivacaine. The results of the pilot study showed that dexmedetomidine has a more analgesic effect than fentanyl and the requirement for a second dose local anesthetic was of $14.4 \%$ in dexmedetomidine group, and $32.5 \%$ in fentanyl group. Taking power 0.8 and alpha error 0.05 , a minimum sample size of 85 patients was calculated for each group. 170 parturients with a fullterm pregnancy were assessed in the study and scheduled for epidural anesthesia during labor. The inclusion criteria were full term pregnancy, active labor with cervical dilatation $>4 \mathrm{~cm}$, intact membrane, uterine contractions occurring at least every 5 minutes, normal cardiotocography (baseline fetal heart rate $120-160 \mathrm{bpm}$, baseline variability $>5$ beats/ minute, the presence of accelerations). The exclusion criteria were coagulopathy, cardiac diseases, pregnancy-induced hypertension, the refusal the epidural anesthesia, accidental dural puncture, rapid progress of labor (delivery in less two hours of study period), and hypersensitivity to local anesthetic, dexmedetomidine or fentanyl.

\section{Anesthetic technique}

In the labor ward, intravenous line G18 was inserted for all parturients and an infusion of $500 \mathrm{ml}$ Ringer lactate solution was started. Monitors such as ECG, pulse oximetry, and blood pressure cuff were attached to the included parturients. Under complete sterilization and local anesthesia, an epidural set ( Perican ${ }^{\circledast}$ needle G18, catheter G27, B. Braun Melsungen AG Germany) was used. The epidural needle was inserted into the epidural space at the L3-4 or L4-5 interspace while the parturients were in the sitting position. The epidural space was identified using the loss of resistance to saline technique $(1-2 \mathrm{ml})$. A multiorifices epidural catheter was inserted $3 \mathrm{~cm}$ into the epidural space through the needle and secured. A test dose of $3 \mathrm{ml}$ of $2 \%$ lidocaine was administered through the catheter after aspiration showed no blood or cerebrospinal fluid coming from the epidural catheter. The study medications were administered 6 minutes after the test dose. The cases were classified into two groups (each $=85$ ): Group D (dexmedetomidine group): The patients received $13 \mathrm{ml}$ of $0.25 \%$ bupivacaine and $1 \mu \mathrm{g} / \mathrm{kg}$ dexmedetomidine diluted in $2 \mathrm{ml}$ saline. Group F (fentanyl group): The patients received $13 \mathrm{ml}$ of $0.25 \%$ bupivacaine and $1 \mu \mathrm{g} / \mathrm{kg}$ fentanyl diluted in $2 \mathrm{ml}$ saline.

The sensory block was assessed by pin prick and cold application every 5 minutes until the onset of sensory block (The time from epidural injection to onset of analgesia) using a 3 -point scale: $0=$ normal sensation, $1=$ loss of sensation of pin prick (analgesia), and $2=$ loss of sensation of touch (anesthesia). The motor block was assessed by Bromage three point score for the lower extremity (0-3), 0: no motor impairment (able to move the hip, knee, and ankle joints); 1: unable to raise either extended leg (able to move joints of knee and ankle); 2 : unable to raise extended leg and flex knee (able to move the joint of ankle); 3; unable to move the knee and foot [14]. The pain relief was assessed by the pain verbal scale from 0 to $4(0$ : complete pain relief; 1 : only slight pain; 2 : a lot of pain relief, 3: little pain relief; 4: no pain relief) [15]. The level of sedation was assessed by a modified Wilson sedation scale from 1 to 4 [16]. Duration of analgesia was assessed by meassuring the time between onset of sensory block and a return of pain sensation. If the block was inadequate or the patient has a pain, another dose of study medication and local anesthetic was administered. The maternal hypotension (mean arterial blood pressure $<20 \%$ of the baseline reading) was managed by the fluids administration, bolus doses of ephedrine $(5-10 \mathrm{mg})$ and left lateral tilting of the parturient. The bradycardia (heart rate $<60 \mathrm{bpm}$ ) was managed with bolus doses of atropine $(0.02 \mathrm{mg} / \mathrm{kg})$. The monitors included the heart rate, maternal arterial blood pressure, arterial oxygen saturation, and fetal heart rate. The readings were recorded every 5 minutes for the first 30 minutes, then every 15 minutes until the end of the labor. The fetus was monitored by a continuous cardiotocography (Fetal Actoccardiograph, MT-516 EBISH-NISHI. SHBUYA-KU.TOKYO, Japan) before labor and by Apgar score and umbilical cord PH after labor. The umbilical cord blood sample was withdrawn by the pediatrician in the delivery or operative room.

\section{The statistical analysis}

Data were statistically described in terms of range; mean \pm standard deviation $( \pm \mathrm{SD})$, frequencies (number of cases) and relative frequencies (percentages) when appropriate. Comparison of quantitative variables between the study groups were done using Mann Whitney $U$ test and one-way or two-way or repeated ANOVA for normally distributed variables. For comparing categorical data, Chi square $\left(c^{2}\right)$ test was performed. Exact test was used instead when the expected frequency is less than 5 . A probability value ( $p$ value) less than 0.05 was considered statistically significant. All statistical calculations were done using computer programs Microsoft Excel version 7 (Microsoft Corporation, NY, USA) and SPSS (Statistical Package for the Social Science; SPSS Inc., Chicago, IL, USA) statistical program for Microsoft Windows.

\section{Results}

Figure 1 shows the CONSORT diagram for the flow of participants through each stage of the present study. All cases completed the study. There was no statistical difference regarding the demographic data, ASA class, parity, gestational and the 


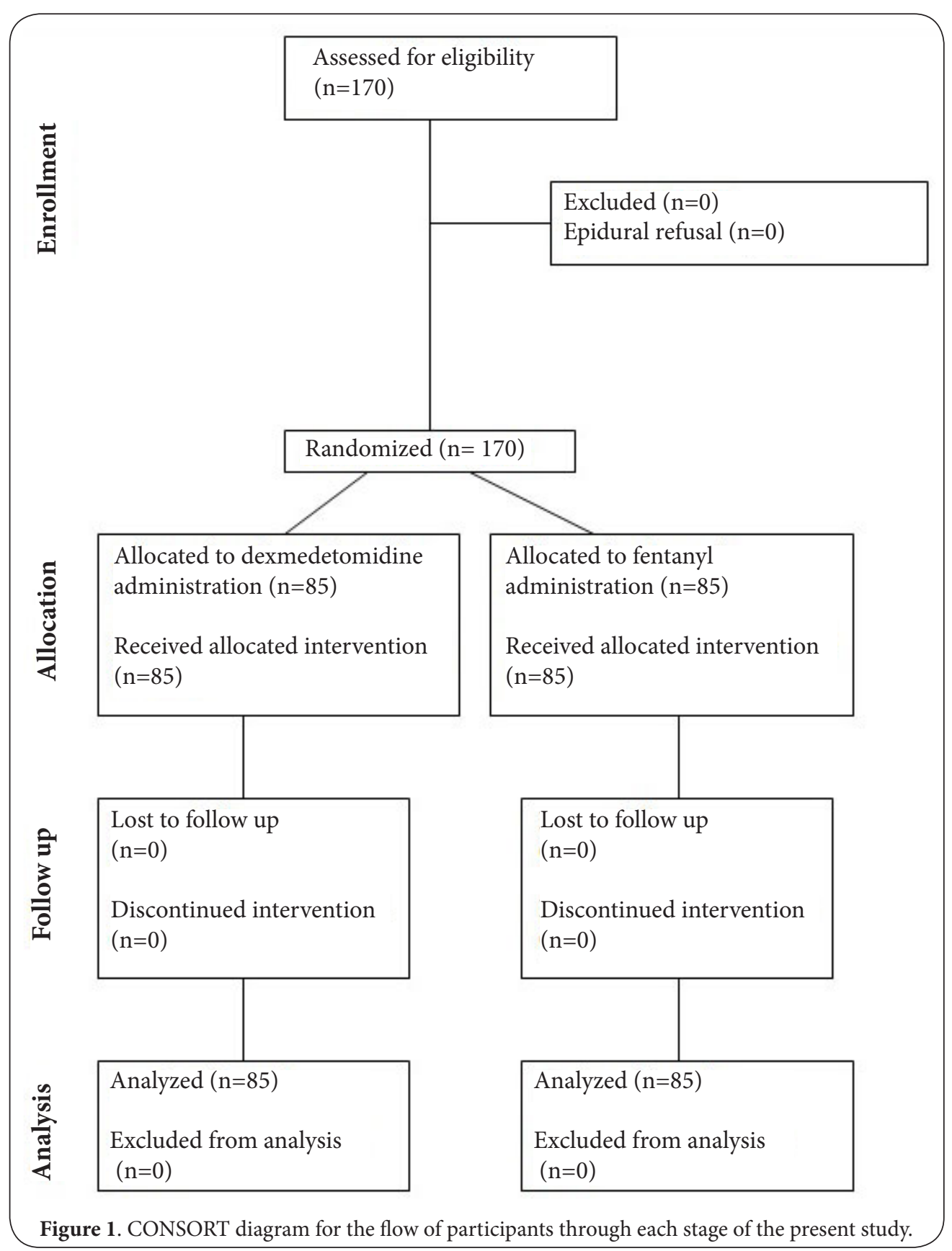

degree of cervical dilatation ( $p>0.05$ ) (Table 1).

Table 2 shows the outcomes of epidural blocks. All parturients of both groups received a single dose of bupivacaine, but 12 cases in dexmedetomidine group and 28 cases in the fentanyl group required a second dose with statistical difference between the two groups $(p=0.003)$. The onset of sensory block was earlier in the dexmedetomidine group more than the fentanyl group $(p=0.011)$ and the duration of analgesia was longer in the dexmedetomidine group compared to the fentanyl group ( $p=0.001)$. The quality of pain relief was better in the dexmedetomidine group than the fentanyl group. The comparison of sensory block level between the two groups was insignificant ( $p>0.05)$. The incidence of motor block was higher in the dexmedetomidine group compared to the fentanyl group ( $p=0.004)$. The incidence of sedation was 9 patients in dexmedetomidine group and no sedation in the fentanyl group $(p=0.002)$.

Table 3 shows the obstetric and fetal outcomes. There was no significant difference regarding the progress of labor, spontaneous labor, assisted labor, cesarean section, Apgar score, and the umbilical cord $\mathrm{PH}$.

Figures 2 and $\mathbf{3}$ shows the changes in the maternal heart 
Table 1. Demographic data of the parturients (data are presented as mean $\pm \mathrm{SD}$, number).

\begin{tabular}{llll}
\hline Variables & $\begin{array}{l}\text { Group D } \\
(\mathbf{n = 8 5})\end{array}$ & $\begin{array}{l}\text { Group F } \\
(\mathbf{n = 8 5})\end{array}$ & P-value \\
\hline Age(year) & $25.92 \pm 4.60$ & $26.24 \pm 4.99$ & 0.664 \\
Weight $(\mathrm{kg})$ & $79.42 \pm 13.17$ & $77.80 \pm 11.48$ & 0.393 \\
Height $(\mathrm{cm})$ & $167.51 \pm 7.35$ & $165.74 \pm 7.18$ & 0.114 \\
ASA I $\quad 41$ & 37 & 0.707 \\
$\quad$ II & 44 & 48 & 0.736 \\
Parity & $1.80 \pm 1.40$ & $2.12 \pm 1.51$ & 0.182 \\
Gestational age(week) & $38.15 \pm 1.14$ & $38.22 \pm 1.11$ & 0.685 \\
Cervical dilatation(cm) & $5.23 \pm 1.17$ & $5.18 \pm 1.12$ & 0.776 \\
\hline
\end{tabular}

ASA: American Society of Anesthesiologists physical status classification system

Group D: Dexmedetomidine group, Group F: Fentanyl group

Table 2. Outcomes of the epidural block (data are presented as mean $\pm S D$, number).

\begin{tabular}{llll}
\hline Variables & $\begin{array}{l}\text { Group D } \\
(\mathbf{n}=\mathbf{8 5})\end{array}$ & $\begin{array}{l}\text { Group F } \\
(\mathbf{n}=\mathbf{8 5})\end{array}$ & P-value \\
\hline $\begin{array}{l}\text { Single dose of } \\
\text { bupivacaine }\end{array}$ & All patients & All patients & 0.999 \\
$\begin{array}{l}\text { Second dose of } \\
\text { bupivacaine }\end{array}$ & 12 & 28 & 0.003 \\
$\begin{array}{l}\text { Onset of analgesia } \\
\text { (min) }\end{array}$ & $6.55 \pm 1.87$ & $10.70 \pm 2.12$ & 0.011 \\
$\begin{array}{l}\text { Duration of analgesia } \\
\text { (min) }\end{array}$ & $314.54 \pm 38.41$ & $240.63 \pm 25.74$ & 0.001 \\
\hline Pain verbal scale & & & \\
\hline 0 & 58 & 45 & 0.041 \\
1 & 13 & 4 & 0.021 \\
2 & 2 & 8 & 0.050 \\
3 & 9 & 12 & 0.484 \\
4 & 3 & 16 & 0.002 \\
\hline Sensory block level & & & \\
\hline T5 & 24 & 29 & 0.407 \\
T6 & 21 & 25 & 0.489 \\
T7-T10 & 40 & 31 & 0.161 \\
Motor block & 14 & 3 & 0.004 \\
Sedation & 9 & 0 & 0.002 \\
\hline
\end{tabular}

Group D: Dexmedetomidine group, Group F: Fentanyl group

rate and mean arterial blood pressure in the patients of the two groups. The heart rate decreased significantly in the dexmedetomidine group with minimal changes in the fentanyl group $(P>0.05)$. Also the mean arterial blood pressure decreased significantly in the dexmedetomidine group compared to the fentanyl group ( $P>0.05$ ).

Table 4 shows that the incidence of maternal hypotension, bradycardia and dry mouth was higher in the dexmedetomidine group than the fentanyl group and the comparison was significant $(p<0.05)$. The incidence of pruritus, respiratory
Table 3. Obstetric and fetal outcomes (data are presented as mean $\pm S D$, number).

\begin{tabular}{llll}
\hline Variables & $\begin{array}{l}\text { Group D } \\
(\mathbf{n = 8 5})\end{array}$ & $\begin{array}{l}\text { Group F } \\
(\mathbf{n = 8 5})\end{array}$ & P-value \\
\hline Progress of labor (cm/hr) & $1.69 \pm 0.45$ & $1.73 \pm 0.48$ & 0.575 \\
Spontaneous delivery & 68 & 70 & 0.694 \\
Assisted delivery & 4 & 3 & 0.699 \\
\hline Cesarean delivery & & & \\
\hline Total number & 13 & 12 & 0.828 \\
Failure of progress & 10 & 7 & 0.443 \\
Fetal distress & 3 & 5 & 0.468 \\
Birth weight(kg) & $3.24 \pm 0.45$ & $3.19 \pm 0.49$ & 0.489 \\
\hline Apgar score & & & \\
\hline at 1 minute & $7.82 \pm 0.72$ & $7.77 \pm 0.84$ & 0.677 \\
at 5 minute & $9.42 \pm 0.50$ & $9.44 \pm 0.43$ & 0.780 \\
Umbilical cord $\mathrm{PH}>7.2$ & 83 & 82 & 0.649 \\
Umbilical cord $\mathrm{PH}$ & $7.28 \pm 0.06$ & $7.27 \pm 0.04$ & 0.203 \\
\hline
\end{tabular}

Group D: Dexmedetomidine group, Group F: Fentanyl group

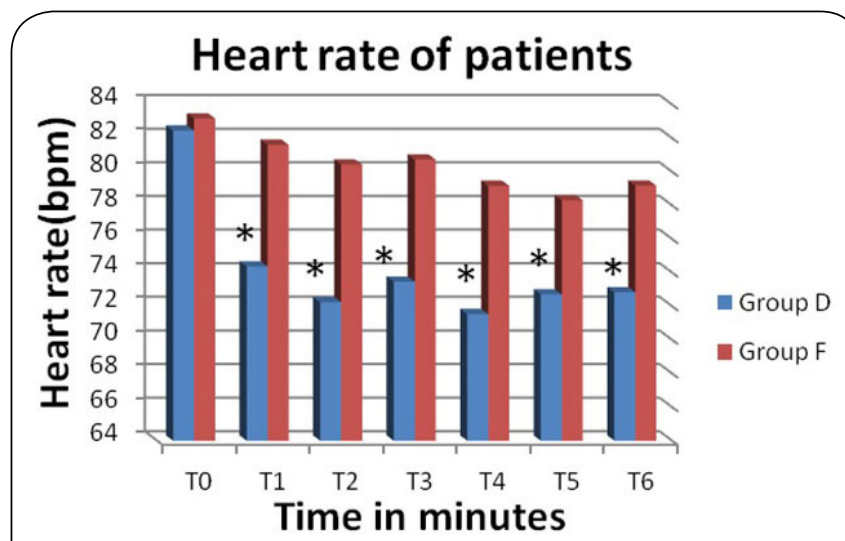

Figure 2. Maternal heart rate of patients.

Group D: Dexmedetomidine group, Group F: Fentanyl group T0: Readings before study medication, T1: Readings 15 minutes after study medication administration, T2: Readings 30 minutes after study medication administration, T3:

Readings 60 minutes after study medication administration, T4: Readings 90 minutes after study medication administration, T5: Readings 120 minutes after study medication administration, T6: Readings 5 minutes before labor.

${ }^{\star} \mathrm{P}<0.05$ significant comparison between the two groups.

depression, nausea and vomiting was lower in the dexmedetomidine group than the fentanyl group and the difference was significant $(p<0.05)$. The incidence of the headache, urine retention and shivering between the two groups was insignificant ( $p>0.05$ ). The incidence of fetal distress (fetal heart rate $<100 \mathrm{bpm}$ ) between the two groups was insignificant $(p=0.468)$. 


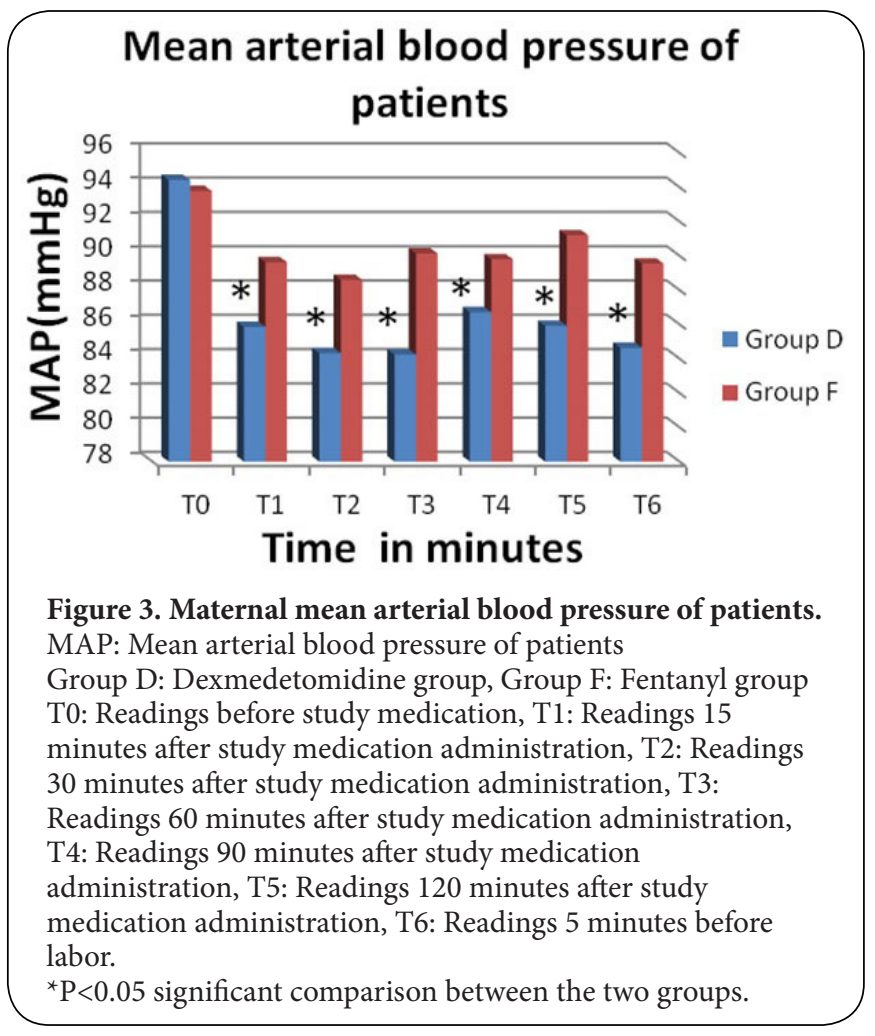

Table 4. Complications of the epidural block (data are presented as number).

\begin{tabular}{llll}
\hline Complication & $\begin{array}{l}\text { Group D } \\
(\mathbf{n = 8 5})\end{array}$ & $\begin{array}{l}\text { Group F } \\
(\mathbf{n}=\mathbf{8 5})\end{array}$ & P-value \\
\hline $\begin{array}{l}\text { Maternal hypotension (Decrease in } \\
\text { MAP }>\text { 20\%) }\end{array}$ & 15 & 6 & 0.035 \\
$\begin{array}{l}\text { Maternal bradycardia (Heart } \\
\text { rate<60 bpm) }\end{array}$ & 14 & 4 & 0.012 \\
Fetal heart rate <100 bpm & 3 & 5 & 0.468 \\
Nausea and vomiting & 5 & 15 & 0.017 \\
Dry mouth & 14 & 3 & 0.004 \\
Pruritis & 0 & 8 & 0.003 \\
Headache & 4 & 3 & 0.699 \\
Respiratory depression & 0 & 5 & 0.023 \\
Urine retention & 0 & 3 & 0.080 \\
Shivering & 3 & 15 & 0.003 \\
\hline
\end{tabular}

\section{Discussion}

The present study showed that the addition of dexmedetomidine to epidural bupivacaine fastens the onset of analgesia and prolongs the duration of analgesia. The quality of analgesia was better with dexmedetomidine group compared to fentanyl group; therefore the incidence of the required second dose of bupivacaine was lower the dexmedetomidine group compared to the fentanyl group. These findings correlate with the result of Selim et al [17]. They reported that the dexmedetomidine shortened the onset with analgesia of bupivacaine and also prolonged the duration of analgesia compared to the addition of fentanyl to the epidural bupivacaine in women undergoing labor and other studies showed the same results [9,18-21].

The present study showed that the incidence of side effects such as the motor block, hypotension, bradycardia, sedation, and dry mouth was higher in the dexmedetomidine group than the fentanyl group. These findings correlate with the study of Selim et al [17]. The study showed that the incidence of maternal hypotension and bradycardia was higher in the dexmedetomidine group than the fentanyl group. A metaanaylsis of 16 studies showed that the most side effects of neuraxial dexmedetomidine were hypotension, bradycardia, and sedation [22]. Another metanaylsis study showed that the dexmedetomidine is associated with a significant requirement to phenylephrine or atropine to manage the hypotension and bradycardia compared to the control group $(p<0.0001)$ [23]. Hanoura et al., [18] evaluated the effect of fentanyl or fentanyl plus dexmedetomidine to the combined spinal-epidural anesthesia for cesarean section. The study showed no significant difference regarding the Apgar scores, the incidence of hypotension, bradycardia, nausea, vomiting, and duration of motor blockade and Salgado et al., [19] found no significant side effect related to the dexmedetomidine to the epidural ropivacaine in patients undergoing hernia repair or varicose vein surgery. But Gupta k et al., [20] found no significant difference in the hemodynamics between the epidural dexmedetomidine-levobupivacaine $(0.5 \%)$ and fentanyl-levobupivacaine $(0.5 \%)$ in patients undergoing vaginal hysterectomy and the same result was shown in patients undergoing cesarean section with combined spinal-epidural anesthesia [24]. The side effects such as pruritus, respiratory depression, nausea and vomiting were lower in the dexmedetomidine group than the fentanyl group and other studies documented the same results $[\mathbf{9 , 1 7 , 2 0 ]}$. The present study showed no difference in the incidence of shivering between the two groups, but Hanoura et al., [18] found the incidence of shivering was lower in the dexmedetomidine group compared to fentanyl group $(p=0.03)$.

Although the systemic maternal effect of dexmedetomidine such as hypotension and bradycardia, there was no effect on the fetus as reflected by the Apgar score and the umbilical $\mathrm{PH}$. Ala-Kokko et al., [25] showed that the fetus is protected as the placenta minimizes the crossing of dexmedetomidine to the fetus [25] and if there is any uteroplacental transfer, it doesn't affect the fetus [26-28]. Palanisamy et al., [28] used intravenous dexmedetomidine as an adjunct to opioid-based PCA and general anesthesia for the labor analgesia and cesarean section in a parturients with favorable maternal and neonatal outcome and the same result were reported by Abu-Halaweh et al [27].

On the other hand, Konaki et al., [29] demonstrated that $10 \mu \mathrm{g}$ of dexmedetomidine $\mathrm{HCl}$ produces moderate to severe demyelination of spinal cord white matter in rabbits following epidural administration. They postulate that low $\mathrm{pH}$ of 
4.5-7.0 of dexmedetomidine is responsible for injury to the myelin sheath; however clonidine with similar $\mathrm{pH}$ (5-7) does not produce neurotoxic side effects [30-32].

The present study and other studies showed the perineural addition of dexmedetomidine to bupivacaine, prolongs the duration of sensory block, motor block, and analgesia, in addition to the decreased requirement to postoperative analgesia. These findings can be explained by the following mechanisms. Dexmedetomidine produces vasoconstriction around the injection site and decreases the absorption of local anesthetics [22], induces local analgesic substances such as enkephalin-like substances [23], decreases the release of proinflammatory mediators [24], increases the release of anti-inflammatory cytokines and modulates the impulse propagation through neurons as a result of interaction with axonal ion channels or receptors [25].

\section{Conclusions}

The epidural dexmedetomidine has many advantages over the fentanyl, where it fastens the onset, prolongs the duration of analgesia, decreases the doses of bupivacaine and the incidence of pruritus, respiratory depression, nausea, and vomiting. Also, it is associated with some disadvantages such as maternal hypotension, bradycardia and motor block. Therefore other studies are recommended to determine the proper dose of epidural dexmedetomidine that does not affect the maternal hemodynamics undergoing labor.

\section{Competing interests}

The authors declare that they have no competing interests.

\section{Authors' contributions}

\begin{tabular}{|l|c|c|}
\hline Authors' contributions & RS & GZ \\
\hline Research concept and design & $\checkmark$ & $\checkmark$ \\
\hline Collection and/or assembly of data & $\checkmark$ & -- \\
\hline Data analysis and interpretation & $\checkmark$ & $\checkmark$ \\
\hline Writing the article & $\checkmark$ & $\checkmark$ \\
\hline Critical revision of the article & $\checkmark$ & $\checkmark$ \\
\hline Final approval of article & $\checkmark$ & $\checkmark$ \\
\hline Statistical analysis & -- & -- \\
\hline
\end{tabular}

\section{Acknowledgement}

The authors thank all staff-nurses in the post anesthesia care unit for their efforts and performance during the study.

Publication history

EIC: D. John Doyle, Case Western Reserve University, USA.

Received: 28-Jan-2016 Final Revised: 02-Mar-2016

Accepted: 25-Mar-2016 Published: 01-Apr-2016

\section{References}

1. Nakamura G, Ganem EM, Rugolo LM and Castiglia YM. Effects on mother and fetus of epidural and combined spinal-epidural techniques for labor analgesia. Rev Assoc Med Bras. 2009; 55:405-9. | Article | PubMed

2. Dilesh PK, Eapen S, Kiran S and Chopra V. A comparison of intrathecal dexmedetomidine verses intrathecal fentanyl with epidural bupivacaine for combined spinal epidural labor analgesia. J Obstet Anaesth Crit Care. 2014; 4:69-74. | Article
3. Onah $\mathrm{HE}$, Obi SN, Oguanuo TC, Ezike HA, Ogbuokiri CM and Ezugworie JO. Pain perception among parturients in Enugu, South-eastern Nigeria. J Obstet Gynaecol. 2007; 27:585-8. | Article | PubMed

4. Boutros A, Blary S, Bronchard R and Bonnet F. Comparison of intermittent epidural bolus, continuous epidural infusion and patient controlled-epidural analgesia during labor. Int J Obstet Anesth. 1999; 8:236-41. | Article | PubMed

5. Benzon HT, Wong HY, Belavic AM, Jr., Goodman I, Mitchell D, Lefheit $T$ and Locicero J. A randomized double-blind comparison of epidural fentanyl infusion versus patient-controlled analgesia with morphine for postthoracotomy pain. Anesth Analg. 1993; 76:316-22. | Article | PubMed

6. Salomaki TE, Laitinen JO and Nuutinen LS. A randomized double-blind comparison of epidural versus intravenous fentanyl infusion for analgesia after thoracotomy. Anesthesiology. 1991; 75:790-5. | Article | PubMed

7. Lorenzini C, Moreira LB and Ferreira MB. Efficacy of ropivacaine compared with ropivacaine plus sufentanil for postoperative analgesia after major knee surgery. Anaesthesia. 2002; 57:424-8. | Article | PubMed

8. Gupta R, Verma R, Bogra J, Kohli M, Raman R and Kushwaha JK. A Comparative study of intrathecal dexmedetomidine and fentanyl as adjuvants to Bupivacaine. J Anaesthesiol Clin Pharmacol. 2011; 27:33943. | Article | PubMed Abstract | PubMed FullText

9. Bajwa SJ, Arora V, Kaur J, Singh A and Parmar SS. Comparative evaluation of dexmedetomidine and fentanyl for epidural analgesia in lower limb orthopedic surgeries. Saudi J Anaesth. 2011; 5:365-70. | Article | PubMed Abstract | PubMed FullText

10. Bajwa SJ, Bajwa SK, Kaur J, Singh G, Arora V, Gupta S, Kulshrestha A, Singh $A$, Parmar $S$ and Goraya $S$. Dexmedetomidine and clonidine in epidural anaesthesia: A comparative evaluation. Indian J Anaesth. 2011; 55:11621. | Article | PubMed Abstract | PubMed FullText

11. Bhana N, Goa KL and McClellan KJ. Dexmedetomidine. Drugs. 2000; 59:263-8. | Article | PubMed

12. Jaakola ML, Salonen $M$, Lehtinen $R$ and Scheinin $H$. The analgesic action of dexmedetomidine--a novel alpha 2-adrenoceptor agonist--in healthy volunteers. Pain. 1991; 46:281-5. | Article | PubMed

13. Talke P, Richardson CA, Scheinin M and Fisher DM. Postoperative pharmacokinetics and sympatholytic effects of dexmedetomidine. Anesth Analg. 1997; 85:1136-42. | Article | PubMed

14. Lew $E$, Yeo SW and Thomas E. Combined spinal epidural anesthesia using epidural volume extension leads to rapid motor recovery after elective caesarean section: a prospective, randomized, double blind study. Anesth Analg. 2004; 98:810-4. | Article

15. Merson N. A comparison of motor block between ropivacaine and bupivacaine for continuous labor epidural analgesia. AANA J. 2001; 69:54-8. | PubMed

16. Nemethy M, Paroli L, Williams-Russo PG and Blanck TJ. Assessing sedation with regional anesthesia: inter-rater agreement on a modified Wilson sedation scale. Anesth Analg. 2002; 94:723-8. | Article | PubMed

17. Selim MF, Elnabtity AM and Hasan AM. Comparative evaluation of epidural bupivacaine - dexmedetomidine and bupivacaine -fentanyl on Doppler velocimetry of uterine and umbilical arteries during labor. $J$ Prenat Med. 2012; 6:47-54. | PubMed Abstract | PubMed FullText

18. Hanoura SE, Hassanin R and Singh R. Intraoperative conditions and quality of postoperative analgesia after adding dexmedetomidine to epidural bupivacaine and fentanyl in elective cesarean section using combined spinal-epidural anesthesia. Anesth Essays Res. 2013; 7:16872. | Article | PubMed Abstract | PubMed FullText

19. Salgado PF, Nascimento P, Módolo NS, Sabbag AT and Silva PC. Adding dexmedetomidine to ropivacaine $\mathbf{0 . 7 5 \%}$ for epidural anesthesia. Does it improve the quality of the anesthesia? Anesthesiology. 2005; 103:974A.

20. Gupta K, Rastogi B, Gupta PK, Jain M, Gupta S and Mangla D. Epidural $0.5 \%$ levobupivacaine with dexmedetomidine versus fentanyl for vaginal hysterectomy: A prospective study. Indian Journal of Pain. 2014; 28:149-54. | Article 
21. Akin S, Aribogan A and Arslan G. Dexmedetomidine as an adjunct to epidural analgesia after abdominal surgery in elderly intensive care patients: A prospective, double-blind, clinical trial. Curr Ther Res Clin Exp. 2008; 69:16-28. | Article | PubMed Abstract | PubMed FullText

22. Wu HH, Wang HT, Jin JJ, Cui GB, Zhou KC, Chen Y, Chen GZ, Dong YL and Wang W. Does dexmedetomidine as a neuraxial adjuvant facilitate better anesthesia and analgesia? A systematic review and metaanalysis. PLoS One. 2014; 9:e93114. | Article | PubMed Abstract | PubMed FullText

23. Klinger RY, White WD, Hale B, Habib AS and Bennett-Guerrero E. Hemodynamic impact of dexmedetomidine administration in 15,656 noncardiac surgical cases. J Clin Anesth. 2012; 24:212-20. | Article | PubMed

24. Yousef AA, Salem HA and Moustafa MZ. Effect of mini-dose epidural dexmedetomidine in elective cesarean section using combined spinalepidural anesthesia: a randomized double-blinded controlled study. J Anesth. 2015; 29:708-14. | Article | PubMed

25. Ala-Kokko TI, Pienimaki P, Lampela E, Hollmen Al, Pelkonen $\mathrm{O}$ and Vahakangas K. Transfer of clonidine and dexmedetomidine across the isolated perfused human placenta. Acta Anaesthesiol Scand. 1997; 41:313-9. | Article | PubMed

26. Nair AS and Sriprakash K. Dexmedetomidine in pregnancy: Review of literature and possible use. J Obstet Anaesth Crit Care. 2013; 3:3-6. I Article

27. Abu-Halaweh SA, Al Oweidi AK, Abu-Malooh H, Zabalawi M, Alkazaleh F, Abu-Ali $\mathrm{H}$ and Ramsay MA. Intravenous dexmedetomidine infusion for labour analgesia in patient with preeclampsia. Eur J Anaesthesiol. 2009; 26:86-7. | Article | PubMed

28. Palanisamy A, Klickovich RJ, Ramsay M, Ouyang DW and Tsen LC. Intravenous dexmedetomidine as an adjunct for labor analgesia and cesarean delivery anesthesia in a parturient with a tethered spinal cord. Int J Obstet Anesth. 2009; 18:258-61. | Article I PubMed

29. Konakci S, Adanir T, Yilmaz $G$ and Rezanko T. The efficacy and neurotoxicity of dexmedetomidine administered via the epidural route. Eur J Anaesthesiol. 2008; 25:403-9. | Article | PubMed

30. Gordh TE, Ekman $S$ and Lagerstedt AS. Evaluation of possible spinal neurotoxicity of clonidine. Ups J Med Sci. 1984; 89:266-73. | Article | PubMed

31. Gordh T, Jr., Post C and Olsson Y. Evaluation of the toxicity of subarachnoid clonidine, guanfacine, and a substance P-antagonist on rat spinal cord and nerve roots: light and electron microscopic observations after chronic intrathecal administration. Anesth Analg. 1986; 65:1303-11. | Article | PubMed

32. Eisenach JC and Grice SC. Epidural clonidine does not decrease blood pressure or spinal cord blood flow in awake sheep. Anesthesiology. 1988; 68:335-40. | Article | PubMed

33. Yoshitomi T, Kohjitani A, Maeda S, Higuchi H, Shimada M and Miyawaki T. Dexmedetomidine enhances the local anesthetic action of lidocaine via an alpha-2A adrenoceptor. Anesth Analg. 2008; 107:96-101. | Article | PubMed

34. Furst $\mathrm{S}$. Transmitters involved in antinociception in the spinal cord. Brain Res Bull. 1999; 48:129-41. | Article | PubMed

35. Kawasaki T, Kawasaki C, Ueki M, Hamada K, Habe K and Sata T. Dexmedetomidine suppresses proinflammatory mediator production in human whole blood in vitro. J Trauma Acute Care Surg. 2013; 74:13705. | Article | PubMed

36. Kosugi T, Mizuta K, Fujita T, Nakashima M and Kumamoto E. High concentrations of dexmedetomidine inhibit compound action potentials in frog sciatic nerves without alpha(2) adrenoceptor activation. Br J Pharmacol. 2010; 160:1662-76. | Article I PubMed Abstract | PubMed FullText

\section{Citation:}

Soliman R and Zohry G. Assessment the effect of fentanyl and dexmedetomidine as adjuvant to epidural bupivacaine in parturients undergoing normal labor. J Anesthesiol Clin Sci. 2016; 5:2.

http://dx.doi.org/10.7243/2049-9752-5-2 